\title{
Monitoring methods and spatial patterns of European canker disease in commercial orchards
}

\author{
R.E. Campbell ${ }^{1}$, S. Roy ${ }^{2}$, T. Curnow ${ }^{1}$ and M. Walter ${ }^{1}$ \\ ${ }^{1}$ The New Zealand Institute for Plant \& Food Research Ltd, Nelson, Old Mill Road, RD3, \\ Motueka, 7198, New Zealand \\ ${ }^{2}$ Institut Technique Tropical, C/o BANAMART, Bois Rouge, 97224 Ducos, Martinique \\ Corresponding author: Rebecca.campbell@plantandfood.co.nz
}

\begin{abstract}
European canker (Neonectria ditissima) kills trees and decreases production in apple orchards. To determine a level of disease control or the extent of its spread in commercial orchards, efficient monitoring methods are required. In this study, we investigated two monitoring methods, sampling a single row and systematic sampling of an orchard block. The spatial pattern of disease within blocks, and whether this changes over time, was also investigated. The accuracy of single-row monitoring depended on the level of canker in the orchard and the patchiness of the distribution of infected trees. However, single-row monitoring tracked changes over time in incidence, severity and type of canker sufficiently well and was efficient. The spatial patterns of disease incidence across the blocks were non-random, but showed hotspots which did not change significantly over time.
\end{abstract}

Keywords Apple, disease monitoring, Neonectria ditissima, spatial disease patterns

\section{INTRODUCTION}

Infection of apple trees by Neonectria ditissima, (European canker) (syn. Nectria galligena, Neonectria galligena) is influenced by a number of environmental and biological factors, including wound and inoculum availability, moisture and temperature (Zeller 1926; Swinburne 1975; Xu et al. 1998; Weber 2014). Both asexual conidia and sexual ascospores are produced in stem cankers and can cause infection. Conidia are produced under a wide range of climatic conditions throughout the year (Swinburne 1975; Latorre et al. 2002) and are dispersed by rain-splash (Creemers 2014). Ascospores, which are produced in perithecia, occur only on older cankers ( $>8$ months) and they can be either rain splashed or dispersed as airborne spores. The importance of ascospores as an inoculum source varies with regional climate (Beresford \& Kim 2011). In areas with warm dry summer conditions, e.g. in New Zealand, ascospores are considered less important than conidia. In addition, the regular removal of older cankers as part of disease control in commercial orchards greatly reduces the occurrence of perithecia.

A simple, effective monitoring system is needed for growers to determine the effectiveness of European canker control strategies. Monitoring is needed to quantify the effect of disease on tree productivity, and to determine whether the disease incidence and severity is increasing or decreasing over time. The disease can be quantified in terms of 
incidence, which is the percentage of diseased trees in an orchard; or severity, which is the intensity of the disease within the trees (Nutter 1991). With appropriate incidence and severity monitoring protocols, growers are able to determine whether the amount of canker in an orchard is reducing, being maintained or increasing.

Since $N$. ditissima conidia are spread between trees primarily by rain-splash, it would be expected that the severity of disease in a tree depends on the number of cankers present in the surrounding trees (Johnson et al. 1982) and that the spatial pattern of disease incidence in an orchard would be patchy (Johnson et al. 1982; Creemers 2014). Because of a patchy distribution, an unbiased estimate of overall canker incidence in a large orchard is difficult to obtain without a prohibitively large amount of effort. This study had three aims: 1) To investigate whether monitoring a single row accurately represents the change in incidence and severity of canker compared with systematic or whole-orchard sampling; 2) To investigate the types of canker expressed and how they change over time in order to guide disease management; and 3) To investigate the spatial pattern of canker within an orchard and how this changes over time, to improve the understanding of mechanisms of spread in commercially-managed orchards.

\section{MATERIALS AND METHODS Orchards}

Six commercial blocks were selected for the monitoring method comparison of single-row

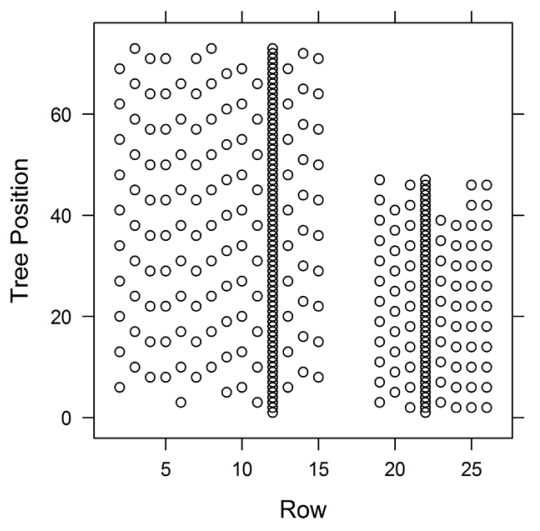

Figure 1 An example of the sampling scheme for the comparison of single-row and systematic sampling methods, showing locations of systematically selected trees and the single rows in two areas in each of the six orchard blocks.

vs systematic sampling (Table 1). The trees in these six blocks were all on dwarfing rootstocks (primarily on 'M9') and were $>10$ years old. Growers adhered to their own fungicide application schedules, which included 3-5 applications of captan during the leaf fall period (4 May 2015 to 17 June 2015), together with the previous spring and summer fungicide applications to control black spot (Venturia inaequalis) and powdery mildew (Podosphaera leuchotrica). A further two commercial blocks were used for the long-term spatial pattern study (Block 7, 8, Table 1). Blocks 7 and 8 were on dwarfing 'M9'

Table 1 Commercial orchards used for the sampling method comparison (blocks 1-6) and the longterm spatial pattern study (blocks 7,8).

\begin{tabular}{ccll}
\hline Block & Grower & Location & Cultivar \\
\hline 1 & 1 & Lower Moutere & 'Scifresh'/ Jazz' \\
2 & 1 & Lower Moutere & 'Scifresh'/ Jazz' \\
3 & 2 & Riwaka & 'Scifresh'/ Jazz' \\
4 & 2 & Riwaka & 'Scifresh'/ Jazz' \\
5 & 3 & Moutere & 'Scifresh'/ Jazz' \\
6 & 4 & Mariri & 'Galaxy' \\
7 & 5 & Hope & 'Scifresh'/ Jazz' \\
8 & 5 & Hope & 'Brookfield' \\
\hline
\end{tabular}


rootstocks, planted in 2003 and 1996 respectively.

\section{Sampling methods}

Each orchard block (blocks 1-6) was divided into two halves, with each half having complete rows. The single rows (one in each half of each orchard block), in which every tree was monitored, were randomly chosen after excluding the outer four rows of the half. For the systematic sampling, a similar number of trees was sampled to the single-row monitoring, but evenly across a number of rows (Figure 1).

The first tree down each row was chosen at random (from the first 15), then all subsequent trees were selected at even intervals. It has been shown that in this context the systematic sampling is equivalent in purpose to stratified random sampling (by row) (Quinn \& Keough

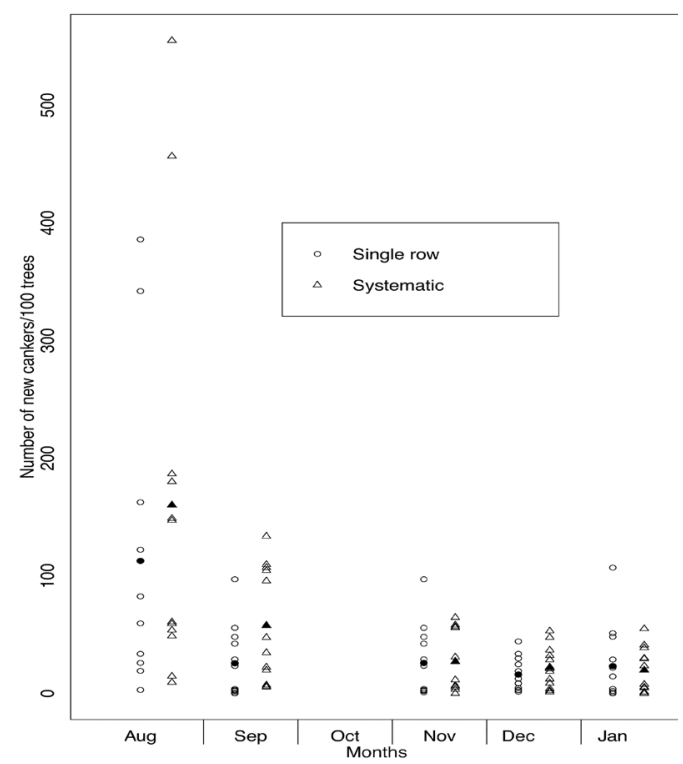

Figure 2 Comparison of the single-row and systematic sampling methods for monitoring European canker in blocks 1-6. Hollow symbols are the means of each half block, solid symbols the means of each monitoring method for all blocks. Sampling methods are offset for clarity. August includes existing background canker severity at the start of this project, whereas the following months are new cankers only.
2002) and is simpler, reducing the chance of errors. This resulted in $80-140$ trees per half block with trees being 6-12 trees apart, depending on overall block size, the number of rows and the number of trees per row. These systematically selected trees were identified with a striped flagging tape for easy identification each month.

Disease severity was assessed monthly from August 2015 to January 2016 (excluding October), with the single-row and systematic sampling trees being assessed within two days of each other (except in August and September when these were several days to two weeks apart). For each disease assessment date, the change in European canker severity was determined as the number of new cankers per tree. These were categorised by type of lesion into trunk, spur, branch and leaf scar cankers (annual cankers). Cankers were marked with Dazzle ${ }^{\mathrm{Tm}}$ spray paint to avoid re-recording of cankers at the next assessment.

Canker incidence (presence or absence) was recorded at the time of winter pruning for every tree in blocks 7 and 8 (Table 1) to investigate the change in disease incidence and location over time. Trees with one or more cankers were marked by the grower with flagging tape each time they pruned for canker. A tree was identified as having canker only once per season, using a separate colour in each season (changing each August). Therefore, annual orchard mapping in winter determined tree incidence for the block.

\section{Data analysis}

To investigate the differences between monitoring methods (single row vs systematic), average numbers of new lesions per tree were plotted grouped by sampling method. Proportions of the different types of cankers were also plotted over time, grouped by sampling method.

The spatial distribution of canker incidence (block 7 and 8) was plotted to show the location of infected trees. This distribution of incidence was tested for complete spatial randomness using the maximum absolute deviance (MAD) test. The similarity between successive assessments was measured as the proportion of the trees that had 


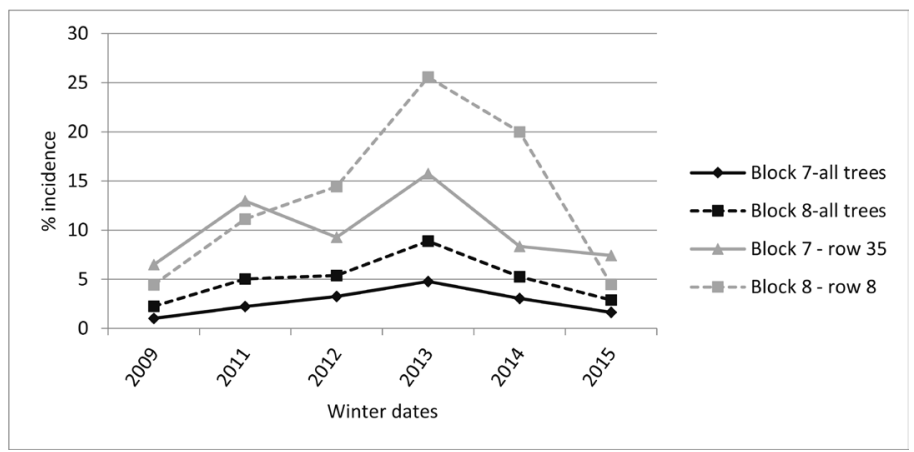

Figure 3 Percentage of trees with canker (incidence) in blocks 7 and 8 and the comparison between the whole block and a single row traversing a canker hotspot. Canker was recorded once in the winter months each year.

the same status at both times. This proportion was compared with the results from 10,000 simulations in which the data for the second data period were generated by randomly choosing the number of infected trees from a binomial distribution with the probability of infection equal to the proportion observed and assigning these infections randomly to tree locations.

All analyses were undertaken using R3.2.2 (R Development Core Team 2015) and the MAD test was performed using the spatstat package (Baddeley et al. 2015).

\section{RESULTS}

The more canker in the block, the better was the relationship between single and systematic

Figure 4 The proportions of the different types of canker (branch, trunk, spur, leaf scar) monitored during August 2015-January 2016, for each sampling occasion over time: a) Systematic monitoring, b) single-row monitoring. August includes existing background canker severity at the start of this project, all other months are new canker. sampling. However, there was a lot of variation in disease levels between blocks. The average number of lesions per 100 trees ranged from 3 to 158 for grower blocks 1-6. Using a single row identified the comparative relative expression of new canker

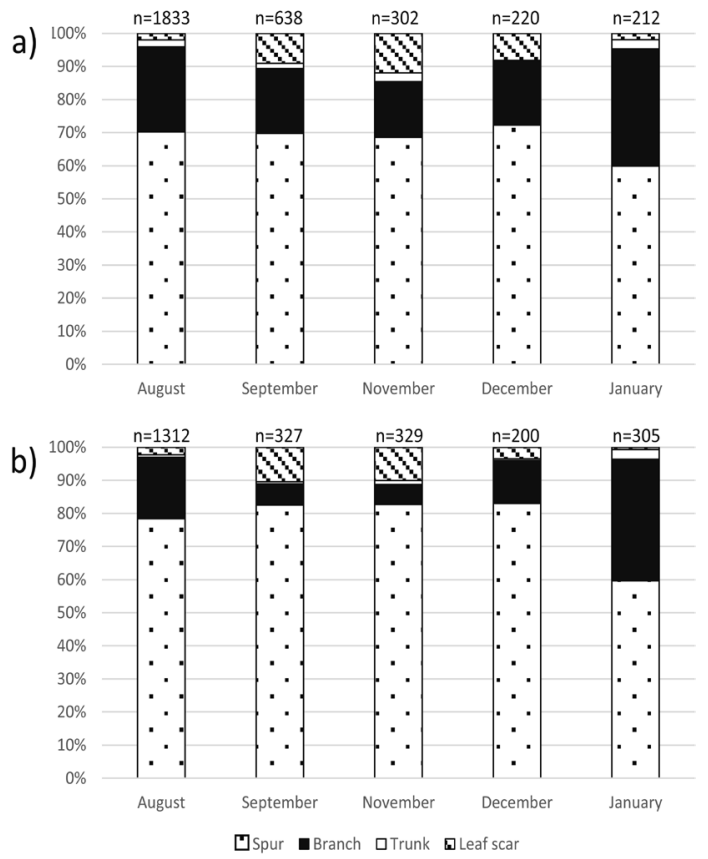



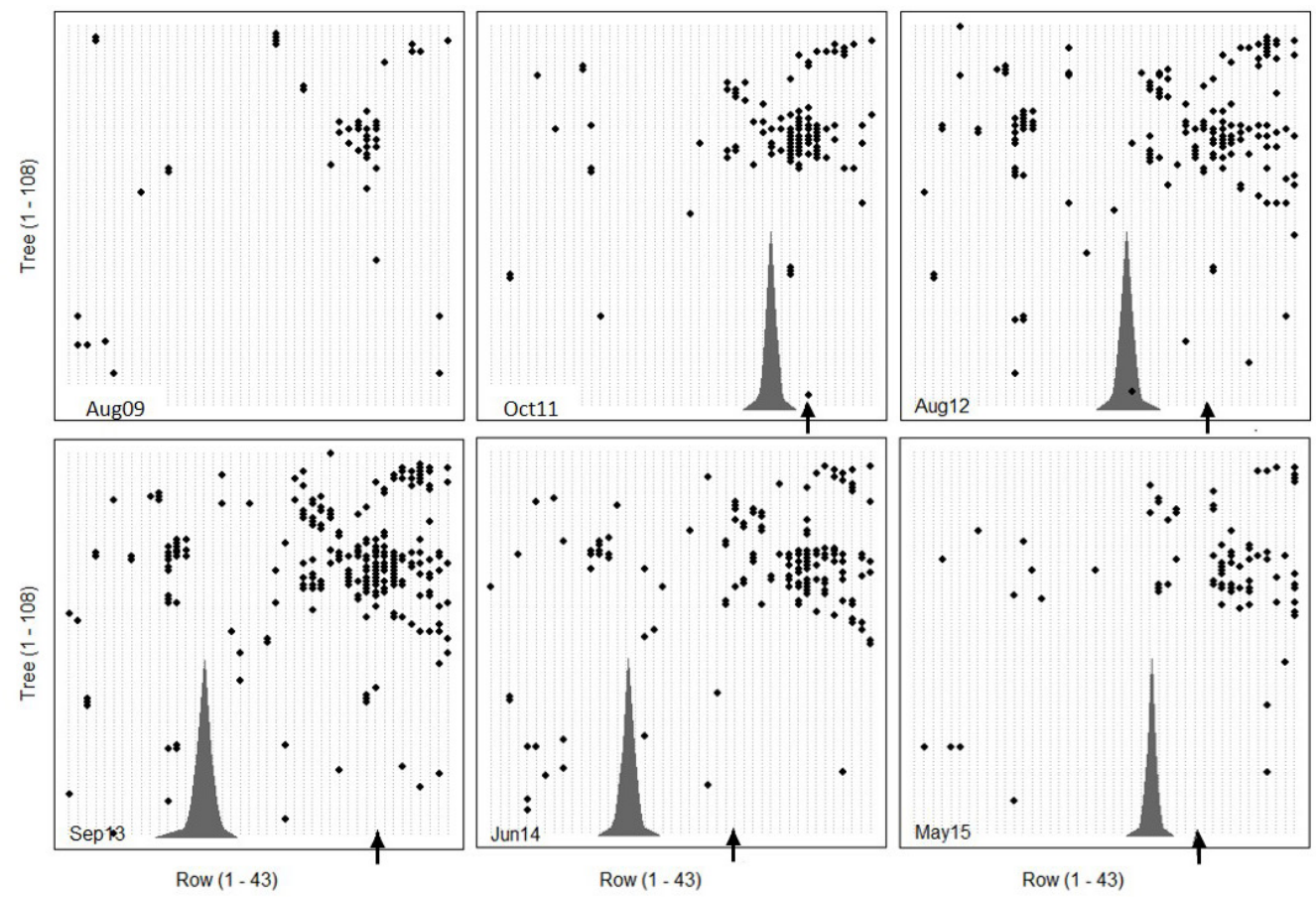

Figure 5 The spatial pattern of tree incidence in block 7. The location of trees (light grey small dots that resemble dotted lines) with trees recorded as infected shown by much larger black dots. The histograms show the expected distribution of similarities from the 10,000 simulations, and the arrow indicates the observed similarity to the previous sampling occasion.

lesions from the existing baseline assessment in August 2015 to new lesion developing by January 2016 (Figure 2). This demonstrated that when randomly chosen, the single row could either over- or under-represent canker incidence in the whole block. However, if the single row was chosen to traverse through a canker hotspot, it over-estimated the incidence of canker compared to the whole block, but indicated the same trend in the change in infection levels over time (Figure 3).

The type of cankers found (trunk, branch, spur, leaf scar) in blocks 1-6 varied between months, with the most prevalent being spur cankers (Figure 4). The relative proportions of the various types of canker lesions were similar between blocks, irrespective of whether the blocks had high or low canker severity initially. Spur cankers were most prevalent across all sampling times. The proportions of each type of canker (average of all blocks) changed over time, with the proportion of leaf scar cankers highest in SeptemberNovember, the proportion of spur cankers highest in November-December and the proportion of branch cankers highest in January (Figure 4). It is noteworthy that the decrease in spur cankers and increase in branch cankers in January can be partially attributed to spur lesions developing into branch lesions. The relative proportions in canker types, however, remained stable regardless of single row or systematic sampling methods, with the exception of branch cankers in September, where there may have been pruning activity between sampling occasions of the two methods.

The spatial distribution of infection for both blocks 7 and 8 was non-random with obvious hotspots of infected trees (Figure 5). Maximum absolute deviance (MAD) indicated that at all sampling times for both blocks, the spatial distribution of the infected trees was significantly 
non-random. This spatial pattern did not change significantly from one year to the next, with the observed similarity consistently greater than the maximum expected similarity observed in the 10,000 simulations (the arrow is always to the right of the histogram, Figure 5).

\section{DISCUSSION Monitoring methods}

Monitoring a single row was at least twice as fast and required less labelling than systematic sampling. For the grower, walking along a single row is an easy way to assess the disease level in their block. However, a simple comparison of systematic sampling vs single row sampling was complicated by the variable amount of canker in a given orchard and the spatial patchiness of the infected trees. Nevertheless, single-row monitoring can be used successfully for determining European canker disease development, as discussed below, with some important acknowledgement of the limitations of a simplified monitoring method.

Single-row monitoring was effective for monitoring the change in incidence, severity and proportion of different types of canker lesion over time. Whether canker incidence was increasing or decreasing between assessments was able to be determined by monitoring a single row. However, the accuracy of a direct comparison of single-row or systematic monitoring for measuring the total amount of canker in the whole orchard varied too much between blocks to make a generalised conclusion. However, in blocks with moderate amounts of canker without extreme hotspots, it could be adequate. Some of the variability in August and September results could be because sampling the single row was not necessarily within two days of the systematic sampling, therefore differences could have been caused by differences in the dates on which assessments were carried out, particularly if there were canker pruning activities in that time. However, the general conclusions would remain the same.

In blocks with hotspots, gradients or strong spatial variability in disease (e.g. block 7), a single row should be carefully selected and will be dependent on the orchard. It is important to consider natural gradients in soil condition or moisture, which could result in more diseased trees in such areas (Zeller 1926), when deciding the selection of monitoring rows. For grower monitoring, a row that traverses through a hotspot or targets the most affected part of block (known from routine canker pruning) will be a conservative indicator of change, and importantly several rows may be needed where canker is particularly patchy. A single row through a hotspot of disease overestimated the incidence of canker for the orchard, but followed the same trend of increase or decrease in total cankers and the same relative proportions of types of cankers (e.g. spur) observed in the orchard.

The simplicity of single-row sampling allows more frequent monitoring by growers for general changes, such as the increase or decrease of canker lesions. Further to monitoring the incidence of canker for physical removal and management, monitoring the change in canker over time can help determine where and when management methods need to be prioritised. For example, by counting the different types of cankers, this study showed that spur infections (from picking wounds) were the major source of new infections. Spur infections developed into branch cankers if left uncontrolled (i.e. not removed). Therefore, disease management during fruit picking will be very important to curb ongoing infections and single-row monitoring is sufficient for this type of information gathering or targeted management goals. If more detailed information is required (e.g. disease spread across the orchard), a more sophisticated spatial selection of trees or rows for monitoring would be required.

\section{Spatial patterns}

In the orchard blocks (7 and 8) where every tree was monitored for canker incidence, this study found obvious spatial patterns across blocks that were consistent over several years. Johnson et al. (1982) also found that the number of cankers found in a tree was directly related to the number of cankers in the surrounding trees due to the nature of dispersal by N. ditissima. Despite yearly 
or more frequent removal of canker, the same trees or patch of trees that were infected remained similarly infected over the period of six years. This illustrates that the patchiness and spatial pattern of disease spread for $N$. ditissima can be stable over time. The consistent spatial pattern could mean either the cankers were accidentally missed for removal, the infection was not completely removed (systemic, latent infections), or that cankers were not removed quickly enough to prevent new infections which expressed at a later sampling time, but in the same location. It has been shown that canker infection can remain latent for up to three years (McCracken et al. 2003), although disease is commonly expressed within months (Amponsah et al. 2015). Early disease detection methods, and potentially whole tree removal, could be warranted for long-term disease control across the entire orchard. On the other hand, if the stable spatial pattern of disease is due to infrequent removal of lesions, this could be more easily managed by increasing the pruning frequency.

\section{CONCLUSIONS}

This study showed that a single-row sampling method can be effective for the purpose of monitoring the change in canker in commercial orchards. It does not necessarily give an accurate measure of absolute levels of canker in an orchard, but the proportion of infection types and the disease progression is well-captured. We do, however, caution that this single row should not be randomly chosen, but chosen to transect the most highly infected part of the orchard for a 'worst case scenario' indicator that would effectively monitor changes in canker incidence and severity. Because of the way $N$. ditissima disperses, there is often a strong patchy spatial pattern of infection across orchards. Growers should get to know their orchard's canker pattern with regular pruning and recording. Nevertheless, while single-row monitoring is sufficient for certain monitoring aims, it will have limitations and the information it can provide depends on the orchard and monitoring purposes.

\section{ACKNOWLEDGEMENTS}

We are grateful to the growers for providing access to their orchards and disease data. We thank Jason Smith and Dean Rainham for providing and sharing the single-row monitoring data. Many thanks to Peter Alspach who helped with the statistical analyses. The work was funded by Pipfruit New Zealand Inc. and the Ministry for Primary Industries via Sustainable Farming fund project SFF 13-040, Plant \& Food Research as part of the Better Border Biosecurity (B3) (www.b3nz.org) research collaboration and Plant \& Food Research Core funding.

\section{REFERENCES}

Amponsah NT, Walter M, Beresford RM, Scheper RWA 2015. Seasonal wound presence and susceptibility to Neonectria ditissima infection in New Zealand Apple trees. New Zealand Plant Protection 68: 250-256.

Baddeley A, Rubak E, Turner R 2015. Spatial point patterns: methodology and applications with R, Chapman and Hall, CRC Press.

Beresford RM, Kim KS 2011. Identification of regional climatic conditions favorable for development of European canker of apple. Phytopathology 101: 135-146.

Creemers P 2014. Nectria canker. In: Sutton TB, Aldwinnkle HS, Agnello AM, Walgenback JF ed. Compendium of apple and pear diseases and pests. $2^{\text {nd }}$ edition. APS Press, St Paul, Minnesota, USA. Pp 49-51.

Johnson DL, Doust JL, Eaton GW 1982. The effect of European canker and its spatial pattern on four apple cultivars in British Columbia. Journal of Applied Ecology 19(2): 603-609

Latorre BA, Rioja ME, Lillo C, Munoz M 2002. The effect of temperature and wetness duration on infection and a warning system for European canker (Nectria galligena) of apple in Chile. Crop Protection 21: 285-291. 
McCracken AR, Berrie A, Barbara DJ, Locke T, Cooke LR, Phleps K, Swinburne TR, Brown AE, Ellerker B, Langrell SRH 2003. Relative significance of nursery infections and orchard inoculum in the development and spread of apple canker (Nectria galligena) in young orchards. Plant Pathology 52(5):553-566.

Nutter FW Jr 1991. Disease assessment terms and concepts. Plant Disease 75(11): 1187-1188.

Quinn GP, Keough MJ 2002. Experimental design and data analysis for biologists. Cambridge University Press. Cambridge, UK.

$\mathrm{R}$ development Core Team 2014. R3.2.2 version 3.2.3. https://www.R-project.org/_R: a language and environment for statistical computing, $\mathrm{R}$ Foundation for Statistical Computing, Vienna, Austria, ISBN 3-90005107-0.
Swinburne TR 1975. European Canker of Apple (Nectria galligena). Review of plant pathology 54(10): 787-799.

Weber RWS 2014. Biology and control of the apple canker fungus Neonectria ditissima (syn. N. galligena) from the Northwestern European perspective. Erwerbs-Obstbau DOI 10.1007/s10341-014-0210-x.

Xu X, Butt DJ, Ridout S 1998. The effects of inoculum dose, duration of wet period, temperature and wound age on infection by Nectria galligena of pruning wounds on apple. European Journal of Plant Pathology 104(5): 511-519.

Zeller SM 1926. European canker of pomaceous fruit trees. Oregon Agricultural College Experimentation Station, station bulletin 222. 